\title{
Effects of dietary components on testosterone metabolism via UDP-glucuronosyltransferase
}

\section{Carl Jenkinson, Andrea Petroczi and Declan P. Naughton*}

School of Life Sciences, Kingston University, Kingston upon Thames, UK

Edited by:

Lena Ekström, Karolinska Institutet, Sweden

Reviewed by:

Cheryl A. Frye, University of Alaska Fairbanks, USA

Lena Ekström, Karolinska Institutet, Sweden

\section{*Correspondence:}

Declan P. Naughton, School of Life

Sciences, Kingston University,

Penrhyn Road, Kingston upon

Thames, Surrey KT1 2EE, UK

e-mail:d.naughton@kingston.ac.uk
The potential interference in testosterone metabolism through ingested substances has ramifications for: (i) a range of pathologies such as prostate cancer, (ii) medication contraindications, (iii) disruption to the endocrine system, and (iv) potential confounding effects on doping tests. Conjugation of anabolic steroids during phase II metabolism, mainly driven by UDP-glucuronosyltransferase (UGT) 2B7, 2B15, and 2B17, has been shown to be impaired in vitro by a range of compounds including xenobiotics and pharmaceuticals. Following early reports on the effects of a range of xenobiotics on UGT activity in vitro, the work was extended to reveal similar effects with common non-steroidal anti-inflammatory drugs. Notably, recent studies have evidenced inhibitory effects of the common foodstuffs green tea and red wine, along with their constituent flavonoids and catechins. This review amalgamates the existing evidence for the inhibitory effects of various pharmaceutical and dietary substances on the rate of UGT glucuronidation of testosterone; and evaluates the potential consequences for health linked to steroid levels, interaction with treatment drugs metabolized by the UGT enzyme and steroid abuse in sport.

Keywords: UGT2B17, inhibition, testosterone, glucuronidation, green tea, red wine, catechins, flavonoids

\section{INTRODUCTION}

As a major route for excretion of exogenous and endogenous compounds, there is considerable interest in the roles of the UDP-glucuronosyltransferase (UGT) family, which has led to widespread investigations of their potential effects in health and disease (1-4). In particular, genetic and chemical modification of UGT activity relating to steroid metabolism has ramifications for a range of pathologies such as prostate cancer, medication contra-indications, disruption to the endocrine system, and potential confounding effects on doping tests in sport. Therefore, it is timely to review lifestyle factors that affect UGT activity. Variations in the activity of UGT isozymes occur as a result of gender and ethnic origins giving different levels of expression of UGT forms and altered ratios of testosterone/epitestosterone excreted in urine (5). In addition to genetic variations, from a steroid metabolism viewpoint, one current focus of investigation is on the regulation of specific UGT activity via induction or inhibition by exogenous compounds such as pharmaceuticals and dietary components.

Several reports show induction of UGT activity by a range of compounds including phytochemicals and pharmaceuticals (6-8). Early studies reported the effects of drugs and dietary compounds on UGT activity in isolated microsomes or in rats without detailing the specific UGT isozymes involved $(9,10)$. Liver microsomal glucuronidation of estradiol and estrone was inhibited by green and black teas, along with a constituent catechin [(-)-epigallocatechin gallate] and several flavonoids (kaempferol, quercetin, rutin, flavone, naringenin, hesperetin) (11). Green tea polyphenols had a strong inhibitory effect of glucuronidation in vitro and showed a small increase in liver glucuronidation activity against estrone and estradiol was observed in vitro in rats with green tea as the sole fluid source (11). Consequent alterations in steroid metabolism have been debated to have a range of putative effects including varying responses to doping tests, inter-medication interactions, and susceptibility to developing cancer $(2,12)$.

From a treatment perspective, the roles of common compounds, including dietary components have been investigated as UGT inhibitors with a view to enhancing bioavailability of drugs. This approach to impairing metabolism and thus increasing the half-lives of drugs has been the subject of patent protection for a wide range of drugs (raloxifene, 2-methoxyestradiol, irinotecan, estradiol, labetalol, dilevalol, zidovudine, and morphine) using numerous inhibitors from plant origin (epicatechin gallate, epigallocatechin gallate, octyl gallate, propyl gallate, quercetin, tannic acid, benzoin gum, capsaicin, dihydrocapsaicin, eugenol, gallocatechin gallate, geraniol, menthol, menthyl acetate, naringenin, allspice berry oil, $N$-vanillylnonanamide, clovebud oil, peppermint oil, silibinin, and silymarin) (13). Regulation of UGTs by phytochemicals has been reviewed with a focus on cancer prevention (3).

The aim of this review is to present a critical evaluation of the current literature on dietary effects on steroid clearance. To date, the reports have focused on in vitro studies using supersomes, microsomes, and enzymes model systems, with reports of in vivo studies with a focus on UGT2B17 are lacking. Thus, it is apposite to generate a fuller understanding of the role of dietary components before in vivo studies are undertaken.

\section{PHARMACEUTICAL INHIBITORS OF UGT STEROID GLUCURONIDATION}

Early reports demonstrated that a number of compounds interfere with the activity of UGT2B17 which is the major isozyme for clearance of anabolic steroids, having greater than double the activity of the next most active form UGT2A1. Sten et al. 


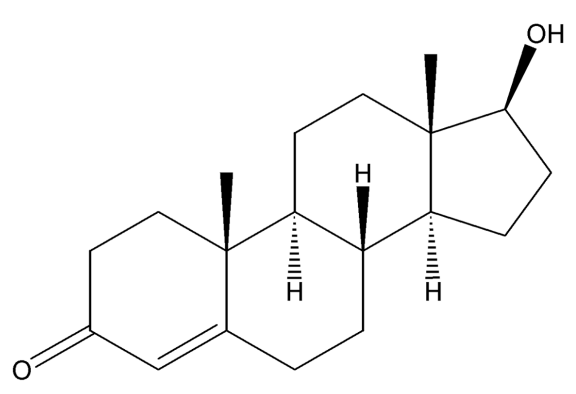

(1)<smiles>O=c1c(O)c(-c2ccc(O)c(O)c2)oc2cc(O)cc(O)c12</smiles>

(3)<smiles>Oc1cc(O)c2c(c1)O[C@H](c1ccc(O)c(O)c1)[C@H](O)C2</smiles>

(2)<smiles>O=C(O[C@H]1Cc2c(O)cc(O)cc2O[C@@H]1c1cc(O)c(O)c(O)c1)c1cc(O)c(O)c(O)c1</smiles>

FIGURE 1 | Structures of testosterone (1) and selected inhibitors: epicatechin (2), quercetin (3), and epigallocatechin gallate (4)

$(14,15)$ reported that epitestosterone and two non-steroidal antiinflammatory drugs (NSAID) act as competitive inhibitors against UGT2B17. Using human microsomes and recombinant enzymes they demonstrated that diclofenac and ibuprofen inhibited testosterone glucuronidation without having significant effects on epitestosterone glucuronidation. Similar inhibitory effects on testosterone glucuronidation were reported for both UGT2B15 and UGT2B17 isozymes in in vitro studies. The authors measured $\mathrm{IC}_{50}$ values for diclofenac inhibition of testosterone glucuronidation by UGT2B15 and UGT2B17 of $25 \mu \mathrm{M}$ and $65 \mu \mathrm{M}$ respectively, at testosterone concentrations of $10 \mu \mathrm{M}$. The corresponding $\mathrm{IC}_{50}$ values for ibuprofen were $121 \mu \mathrm{M}$ and $1340 \mu \mathrm{M}$ against UGT2B15 and UGT2B17 respectively. Kinetic experiments using Dixon plots revealed that the diclofenac acts through competitive inhibition.

To date, no commensurate studies have been reported demonstrating an effect of pharmaceuticals on testosterone glucuronidation in vivo. A recent report showed only a slight modification but no significant effects of concomitant use of maximum recommended doses of ibuprofen or diclofenac with testosterone on the urinary ratios of testosterone/epitestosterone in individuals with either two, one, or no allele of the UGT2B17, and no effect when ibuprofen/diclofenac was administered prior to single dose of testosterone (16). Given the competitive nature of the inhibition, at least for diclofenac, the experiment was limited by restriction to maximum doses of the NSAID. Thus, doses of $50 \mathrm{mg} \times 3$ per day of the single competitive inhibitor, although well reasoned, may not elicit an inhibitory effect given that ibuprofen can also elevate
UGT enzyme activity in vivo (8). Although reports of in vivo studies are lacking to date, the potential effects of inhibiting major testosterone-metabolizing enzymes warrants further exploration, especially if common substances are considered where maximum dosage effects do not limit intake. From one standpoint, this effect could alter the results of a doping test which is based on the ratio of the glucuronidated testosterone and epitestosterone. Following these advances, researchers have recently explored the effects of dietary components on steroid metabolism. The chemical structures of testosterone and selected inhibitors are shown in Figure 1.

\section{DIETARY INHIBITORS OF UGT STEROID GLUCURONIDATION}

Given the growing body of literature regarding: (i) key roles for UGT enzymes in the metabolism a wide range of endogenous and exogenous compounds, (ii) the increasing understanding of the specificity UGT isozymes for varying substrates, and (iii) the roles of many common substances in elevating UGT activity in vivo and reducing UGT activity in vitro; studies on the roles of dietary components on testosterone glucuronidation in vitro were warranted.

Jenkinson et al. (17) first reported the effects of dietary green and white teas on the activity of UGT2B17 toward testosterone glucuronidation. Using an high performance liquid chromatography (HPLC) assay, testosterone glucuronidation was monitored in the presence of tea extracts using human UGT2B17 supersomes. Under the conditions studied, green and white tea preparations inhibited the reaction by circa $20 \%$ with a white tea 
Table 1 | Inhibitory profiles for intact foods and catechins.

\begin{tabular}{ll}
\hline Foods & $\begin{array}{l}\text { Testosterone glucuronidation rate } \\
\text { (ng/mL/min/mg protein) }\end{array}$ \\
\hline Testosterone control $(12 \mu \mathrm{g} / \mathrm{mL})$ & $682.09 \pm 30.73$ \\
Cacao beans & $666.22 \pm 23.55$ \\
Cacao block & $572.89 \pm 20.14$ \\
White tea beard & $249.83 \pm 18.87$ \\
White tea leaf & $246.22 \pm 16.61$ \\
Green tea & $179.56 \pm 22.64$ \\
White tea powder & $69.57 \pm 11.04$ \\
\hline Catechin (250 $\mu$ M) & Testosterone glucuronidation rate \\
& (ng/mL/min/mg protein) \\
\hline Testosterone control $(10 \mu \mathrm{g} / \mathrm{mL})$ & $453.77 \pm 10.24$ \\
Gallocatechin & $446.25 \pm 37.92$ \\
Caffeine & $441.25 \pm 23.75$ \\
Epigallo catechin & $420.42 \pm 27.08$ \\
(-) Epicatechin & $352.08 \pm 20.42$ \\
(+) Epicatechin & $264.17 \pm 15.83$ \\
Epicatechin gallate & $143.75 \pm 13.75$ \\
Epigallocatechin gallate & $99.17 \pm 19.17$ \\
Catechin gallate & $70.42 \pm 7.92$ \\
\end{tabular}

powder inhibiting glucuronidation by $30 \%$. HPLC analysis of the teas revealed key constituents such as epicatechin (EC) and epigallocatechin gallate (EGCG). Analysis via a Dixon plot revealed that EGCG was acting as a competitive inhibitor with an $\mathrm{IC}_{50}$ value of $64 \mu \mathrm{M}$ which equaled that found previously for diclofenac (15). At a concentration of $1 \mathrm{mM}$, EC inhibited testosterone (at $10 \mu \mathrm{M}$ ) glucuronidation by some $55 \%$ (17).

Further studies by the authors, using a different HPLC method, revealed that cacao also inhibits UGT2B17 but to a lesser extent (ca. 15\%) as shown in Table $\mathbf{1}$ (18). Under these conditions, at testosterone concentrations of $12 \mu \mathrm{g} / \mathrm{mL}$, white and green tea preparations inhibited over $70 \%$ of activity with a white tea powder form showing inhibition of some $90 \%$ (Table 1). For the individual phenolics, inhibition was insignificant for gallocatechin and caffeine but ranged up to 22 and $42 \%$ for (-) epicatechin and (+) epicatechin respectively (Table 1). As shown in Table 1, extensive inhibition of testosterone glucuronidation was observed for epicatechin gallate (ca. 70\%), epigallocatechin gallate (ca. 78\%), and catechin gallate (ca. 90\%) (17).

Analysis of the tea and cacao samples by $\operatorname{HPLC}(17,18)$ revealed the catechins displayed in Table $\mathbf{1}$ were present in these samples at lower levels in comparison to the tea samples. The cacao samples, whilst inhibiting testosterone glucuronidation, did so at a

\section{REFERENCES}

1. Angstadt AY, Berg A, Zhu J, Miller P, Hartman TJ, Lesko SM, et al. The effect of copy number variation in the phase II detoxification genes UGT2B17 and UGT2B28 on colorectal cancer risk. Cancer (2013) 119:2477-85. doi: $10.1002 /$ cncr.28009

2. Thind J, Jenkinson C, Naughton DP, Petroczi A. Modulation of UDP glucuronosyltransferase 2B15 and 2B17 and prostate cancer risk. Curr Perspect Adv Cancer

much lesser rate than the tea samples which could be linked with having lower levels of inhibiting catechin compounds at the same concentrations of the tea samples.

In addition, red wine and its constituents were shown to inhibit testosterone glucuronidation by human UGT2B17 supersomes (19). Under the conditions studied, red wine inhibited glucuronidation by up to $70 \%$ over a 2 -h period, with little effect arising from the alcohol content. Phenolic components were selected following HPLC analysis of the selected red wine and quercetin, caffeic acid, and gallic acid inhibited UGT2B17 testosterone glucuronidation by 72,22 , and $9 \%$ respectively, with concentrations of phenolic:testosterone of $100 \mu \mathrm{M}: 250 \mu \mathrm{M}$. For the most active phenolic, reducing the quercetin concentration to $2 \mu \mathrm{M}$, maintained inhibition of $20 \%$ in spite of the 10 -fold excess of testosterone.

\section{DISCUSSION AND FUTURE DIRECTIONS}

Based on the observed effect in vitro, the presence of flavonoids and catechins in a wide range of foodstuffs points to the potential for interaction in vivo with UGT2B17 activity. However, to our knowledge this has yet to be investigated in a clinical setting. Studies have shown oral administration of green tea extract catechins in rats lead to increased plasma testosterone as well as elevating other hormones over 8 weeks (20). The short term effects of iP administration EGCG in rats over 7 days found a number of hormones in serum dropped including testosterone, however hormone levels remained the same when EC, epigallocatechin (EGC), and epicatechin-3-gallate (ECG) were administered (21).

Dietary components inhibiting UGT2B17 could have clinical significance in altering the risk for prostate cancer. A recent review (2) highlights a number of studies that demonstrate an increase risk of prostate cancer with altered UGT2B17 function, although in the midst of conflicting evidence, determining the consequence of UGT2B17 polymorphism in prostate cancer risk has remained inconclusive. In a clinical setting catechins have been analyzed more for their apoptotic activities on prostate cancer cells rather than the links between endocrine levels and prostate cancer (22).

Clearly, the confounding issue of the contrasting effects of elevating enzyme activity, perhaps by induction, and concomitant chemical inhibition of the enzyme, will require rigorous investigation. We need to considerably further our knowledge of the effects of diet on the key UGT isozymes involved in steroid metabolism. This includes effects and mechanisms leading to elevation of enzyme activity but also gaining a full profile of inhibitors. Given the potential for varied responses in different tissues, the roles of UGT2B17 inhibitors as endocrine disrupters (23), developing androgen related pathologies, and in contra-indications to medicines still warrants full investigation.

Res Treat (2013) 2013:812129. doi:10.5171/2013.812129

3. Saracino MR, Lampe JW. Phytochemical regulation of UDPglucuronosyltransferases: implications for cancer prevention. Nutr Cancer (2007) 59:121-41. doi:10.1080/0163558070145 8178

4. Zhong Y, Byrd JC. UGT2B17 as a disease accelerator in CLL. Blood (2012) 121:1067-8. doi:10.1182/blood-2012-12-46 9965 
5. Ekström L, Gök E, Johansson M, Garle M, Rane A, Schulze JJ. Doping and genetic testing: sex difference in UGT2B15 expression, testosterone glucuronidation activity and urinary testosterone/epitestosterone glucuronide ratio. Curr Pharmacogenomics Person Med (2012) 10:125-31. doi:10.2174/ 187569212800626403

6. Mizuma T, Awazu S. Dietary polyphenols (-)-epicatechin and chrysin inhibit intestinal glucuronidation metabolism to increase drug absorption. $J$ Pharm Sci (2004) 93:2407-10. doi:10.1002/jps.20146

7. Van der Logt EMJ, Roelofs HMJ, Nagengast FM, Peters WHM. Induction of rat hepatic and intestinal UDP-glucuronosyl transferases by naturally occurring dietary anticarcinogens. Carcinogenesis (2003) 24:1651-6. doi:10.1093/carcin/ bgg117

8. Van der Logt EMJ, Roelof HMJ, Van Lieshout EMM, Nagengast FM, Peters WHM. Effects of dietary anticarcinogens and nonsteroidal anti-inflammatory drugs on rat gastrointestinal UDP-glucuronosyltransferases.

Anticancer Res (2004) 24: 843-9.

9. Grancharov $\mathrm{K}$, Engelberg $\mathrm{H}$, Naydenova Z, Müller G, Rettenmeier AW, Golovinsky E. Inhibition of UDPglucuronosyltransferases in rat liver microsomes by natural mutagens and carcinogens. Arch Toxicol (2001) 75:609-12. doi:10.1007/s00204-001-0282-x
10. Teyssier C, Amiot M-J, Mondy N, Auger J, Kahane R, Siess MH. Effect of onion consumption by rats on hepatic drug-metabolizing enzymes. Food Chem Toxicol (2001) 39:981-7. doi:10.1016/S02786915(01)00056-4

11. Zhu BT, Taneja N, Loder DP, Balentine DA, Conney AH. Effects of tea polyphenols and flavonoids on liver microsomal glucuronidation of estradiol and estrone. $J$ Steroid Biochem Mol Biol (1998) 64:207-15. doi:10.1016/S09600760(97)00163-5

12. Rathbun RC, Liedtke MD. Antiretroviral drug interactions: overview of interactions involving new and investigational agents and the role of therapeutic drug monitoring for management. Pharmaceutics (2011) 3:745-81. doi:10.3390/ pharmaceutics3040745

13. Wacher VJ, Benet LZ. Use of UGT Inhibitors to Increase Bioavailability. US Patent Application WO03055494A1 (2003).

14. Sten T, Bichlmaier I, Kuuranne $\mathrm{T}$, Leinonen $\mathrm{A}$, Yli-Kauhaluoma J, Finel $\mathrm{M}$. UDP-glucuronosyltransferases (UGTs) 2B7 and UGT2B17 display converse specificity in testosterone and epitestosterone glucuronidation, whereas UGT2A1 conjugates both androgens similarly. Drug Metab Dispos (2009) 37: 417-23. doi:10.1124/dmd.108. 024844

15. Sten T, Finel M, Ask B, Rane A, Ekström L. Non-steroidal antiinflammatory drugs interact with testosterone glucuronidation.
Steroids (2009) 74:971-7. doi:10.1016/j.steroids.2009.07.004

16. Lundmark J, Gårevik N, Thörngren JO, Garle M, Ekström L, Rane A, et al. Nonsteroidal antiinflammatory drugs (NSAIDs) do not influence the urinary testosterone/epitestosterone glucuronide ratio. Front Endocrinol (Lausanne) (2013) 4:51. doi:10.3389/fendo.2013.00051

17. Jenkinson C, Petroczi A, Barker J, Naughton DP. Dietary green and white teas suppress UDP-glucuronosyltransferase UGT2B17 mediated testosterone glucuronidation. Steroids (2012) 77:691-5. doi:10.1016/j.steroids.2012.02.023

18. Jenkinson C, Petroczi A, Barker J, Naughton DP. Effects of food components and the ratio of epitestosterone to testosterone on steroid glucuronidation. Endocrine Abstracts (2013) 32:974. doi:10. 1530/endoabs.32.P974

19. Jenkinson C, Petroczi A, Naughton DP. Red wine and component flavonoids inhibit UGT2B17 in vitro. Nutr J (2012) 11:67. doi:10.1186/1475-2891-11-67

20. Satoh K, Sakamoto Y, Ogata A, Nagai F, Mikuriya H, Numazawa $\mathrm{M}$, et al. Inhibition of aromatase activity by green tea extract catechins and their endocrinological effects of oral administration in rats. Food Chem Toxicol (2002) 40:925-33. doi: 10.1016/S0278-6915(02)00066-2

21. Kao YH, Hiipakka RA, Liao S. Modulation of endocrine systems and food intake by green tea epigallocatechin gallate.
Endocrinology (2000) 141:980-7. doi:10.1210/en.141.3.980

22. Chung LY, Cheung TC, Kong SK, Fung KP, Choy YM, Chan ZY, et al. Induction of apoptosis by green tea catechins in human prostate cancer DU145 cells. Life Sci (2001) 68:1207-14. doi:10.1016/S00243205(00)01020-1

23. Turgeon D, Carrier JS, Chouinard S, Bélanger A. Glucuronidation activity of the UGT2B17 enzyme toward xenobiotics. Drug Metab Dispos (2003) 31:670-6. doi:10.1124/dmd.31.5.670

Conflict of Interest Statement: The authors declare that the research was conducted in the absence of any commercial or financial relationships that could be construed as a potential conflict of interest.

Received: 30 April 2013; paper pending published: 19 May 2013; accepted: 20 June 2013; published online: 08 July 2013. Citation: Jenkinson C, Petroczi A and Naughton DP (2013) Effects of dietary components on testosterone metabolism via UDP-glucuronosyltransferase. Front. Endocrinol. 4:80. doi: 10.3389/fendo.2013.00080

This article was submitted to Frontiers in Experimental Endocrinology, a specialty of Frontiers in Endocrinology.

Copyright (c) 2013 Jenkinson, Petroczi and Naughton. This is an open-access article distributed under the terms of the Creative Commons Attribution License, which permits use, distribution and reproduction in other forums, provided the original authors and source are credited and subject to any copyright notices concerning any third-party graphics etc. 